\title{
Determination of Free Amino Acids in Three Species of Duckweed (Lemnaceae)
}

\author{
Xiaolong Zhang $\mathbb{D}^{1,2,3}$ Hongyan Chen $\mathbb{D}^{1},{ }^{3}$ Dawei Wu $\mathbb{D}^{1,2}$ Wei Gu, ${ }^{1,2}$ Xiao Sun $\mathbb{D}^{4}{ }^{4}$ \\ Jian Chen $\mathbb{1}^{3},{ }^{3}$ and Qinan $\mathrm{Wu}(\mathbb{1})^{1,2}$ \\ ${ }^{1}$ College of Pharmacy, Nanjing University of Chinese Medicine, Nanjing 210023, China \\ ${ }^{2}$ Jiangsu Collaborative Innovation Center of Chinese Medicinal Resources Industrialization, Nanjing 210023, China \\ ${ }^{3}$ Lianyungang Food and Drug Inspection Center, Lianyungang 222000, China \\ ${ }^{4}$ Department of Pharmacy, Lianyungang First People's Hospital, Lianyungang 222002, China
}

Correspondence should be addressed to Qinan Wu; qnwnjucm@163.com

Received 6 July 2018; Revised 22 October 2018; Accepted 18 November 2018; Published 5 December 2018

Academic Editor: Antimo Di Maro

Copyright (c) 2018 Xiaolong Zhang et al. This is an open access article distributed under the Creative Commons Attribution License, which permits unrestricted use, distribution, and reproduction in any medium, provided the original work is properly cited.

\begin{abstract}
In this study, a fast, simple, precise, and sensitive hydrophilic interaction liquid chromatography (HILIC) method was established for simultaneous determination of free amino acids in three different varieties of duckweed including Spirodela polyrhiza (L.) Schleid., Landoltia punctata (G. Mey.) Les \& D. J. Crawford, and Lemna aequinoctialis Welwitsch by ultrahigh performance liquid chromatography coupled with tandem mass spectrometry (UHPLC-MS/MS). Method validation was processed in terms of linearity, precision, stability, repeatability, and accuracy as well as limits of detection and quantification. The developed method was applied for quantification of 59 batches of samples. Then chemometric analysis was used to evaluate different duckweeds by principle component analysis (PCA) and orthogonal partial least squares-discriminant analysis (OPLS-DA). The results demonstrated that there was no significant difference in FAAs' profile among three varieties of duckweed.
\end{abstract}

\section{Introduction}

Amino acids are kinds of nitrogenous components that play vital and diverse roles in metabolism and have attracted significant attention in food, feedstuff, and alimentary supplements. Amino acids are basic units and important ingredients of proteins and involved in the progress of biosynthesis for glycoprotein, porphyrins, neurotransmitters, polyamines, and nitric oxide [1-5]. Nutritional studies show that amino acids can modulate gene expression and enhance the growth of skeletal muscle and small intestine [6].

The family of Lemnaceae colloquially known as duckweed has been consumed as human food since long [7]. Duckweeds have the striking capacity of explosive reproduction [8]. They can grow almost everywhere with appropriate temperature and nutrition in water. But their greatest potential is to produce large quantities of protein-rich biomass that is a promising food resource for humans [9] and is suitable for feeding a wide range of animals including fish, poultry, and cattle [10-12]. The contents of free amino acids (FAAs) are very important for the evaluation of the protein-rich food. Fresh duckweed contains a large amount of water with moisture content of $86 \%-94 \%$. But for dried samples, their protein concentration ranges from $25 \%$ to $40 \%$ with much lower fibrous material than that of land forage [13]. The habitat influences the content of proteins and fibers dramatically. Content of amino acids and protein always depend on their species pattern and growth environment, such as sunshine, nutrition media, and their growth pattern: gregarious or solitary. Under high nutritional conditions, more proteins and fewer fibers are accumulated in duckweed and vice versa. The amino acid type of duckweed is very close to that of animals and thus could be used by animals efficiently $[7,14]$. The first limited amino acid (lysine) is similar to soybean and is more superior to that in other food such as sorghum and maize. 
There are several methods reported in literature for analysis of free amino acids. In general, the FAAs are extracted with solvents water, formic acid, hydrochloric acid, or ethanol, followed by filtration or centrifugation before analysis [15-17]. Several techniques have been described for detection of free amino acids including ionexchange chromatography [18], precolumn derivatization followed by reversed high-performance liquid chromatography coupled with diode array or fluorescence detector $[19,20]$, gas chromatography, mass spectrometry, and capillary electrophoresis [21]. In recent years, determination of FAAs using ultrahigh performance liquid chromatography hyphenated to mass spectrometry has gained great notice because of the merit of selective separation for the polar underivatized analytes under HILIC condition with acetonitrile-dominated mobile phase [22-25].

In present study, a feasible and reliable UPLC-QTRAPMS/MS method was developed and validated for quantitative analysis of 24 underivatized FAAs simultaneously. Multivariate statistical analysis was employed to assess the differences in the profiles of FAAs among three species of duckweed. This simple and fast analytical method would be used for quality control of duckweeds.

\section{Materials and Methods}

2.1. Reagents and Materials. 59 batches of duckweed were collected from different regions in China as shown in Table 1. The samples were identified and classified by PCR [26-28], and the number of populations was as follows: 25 populations from species Spirodela polyrhiza, 16 populations from species Landoltia punctata (its another previously invalid name is Spirodela oligorrhiza (Kurz) Hegelm.), and 18 populations from Lemna aequinoctialis. Fresh materials were washed by tap water, dried in sunshine, and pulverized, and the powder was screened through 60-mesh sieve. Reference standards of tyrosine (Tyr), alanine (Ala), glutamic acid (Glu), phenylalanine (Phe), histidine (His), isoleucine (Ile), aspartic acid (Asp), lysine (Lys), glycine (Gly), valine (Val), citrulline (Cit), cystine (Cys2), proline (Pro), tryptophan (Trp), leucine (Leu), arginine (Arg), cysteine (Cys), hydroxylproline (Hpro), methionine (Met), threonine (Thr), asparagine (Asn), and serine (Ser) were purchased from National Institutes for Food and Drug Control (Beijing, China) with the purity more than $98 \%$. Reference standards of $\gamma$-aminobutyric (GABA) and glutamine (Gln) with the purity more than $98 \%$ were obtained from Aladdin Industrial Corporation (Shanghai, China). Acetonitrile (HPLC grade) was purchased from Merk (Darmstadt, Germany). Formic acid and ammonium formate (HPLC grade) were provided by Mreda Technology Incorporation (USA). Deionized water used for analysis procedure was produced by a Milli-Q Academic ultrapure water system (Millipore, Bedford, MA, USA).

2.2. Instrumentation and Chromatographic and Mass Conditions. Chromatographic analysis was performed on a Shimadzu LC-30 ultrahigh performance liquid chromatography system (Shimadzu, Japan), which consisted of a
TABLE 1: Information of duckweeds from different regions.

\begin{tabular}{|c|c|c|}
\hline Sample & Species & Site \\
\hline SP1-7 & Spirodela polyrhiza & Yangzhou City of Jiangsu Province \\
\hline SP8-9 & Spirodela polyrhiza & Yancheng City of Jiangsu Province \\
\hline SP10-11 & Spirodela polyrhiza & Nanjing City of Jiangsu Province \\
\hline SP12-13 & Spirodela polyrhiza & Huaian City of Jiangsu Province \\
\hline SP14-17 & Spirodela polyrhiza & $\begin{array}{c}\text { Lianyungang City of Jiangsu } \\
\text { Province }\end{array}$ \\
\hline SP18-19 & Spirodela polyrhiza & Linyi City of Shan \\
\hline SP20-21 & Spirodela polyrhiza & Hefei City of Anhui Province \\
\hline SP22-23 & Spirodela polyrhiza & $\begin{array}{c}\text { Hangzhou City of Jiangsu } \\
\text { Province }\end{array}$ \\
\hline SP24-25 & Spirodela polyrhiza & Baoding City of Hebei Province \\
\hline LP1-11 & Landoltia punctata & Yangzhou City of Jiangsu province \\
\hline LP12-16 & Landoltia punctata & Huaian City of Jiangsu province \\
\hline LA1-3 & $\begin{array}{l}\text { Lemna } \\
\text { aequinoctialis }\end{array}$ & Yangzhou City of Jiangsu Province \\
\hline LA4-8 & $\begin{array}{l}\text { Lemna } \\
\text { aequinoctialis }\end{array}$ & Yancheng City of Jiangsu Province \\
\hline LA9-14 & $\begin{array}{l}\text { Lemna } \\
\text { aequinoctialis }\end{array}$ & Nanjing City of Jiangsu Province \\
\hline LA15-16 & $\begin{array}{l}\text { Lemna } \\
\text { aequinoctialis }\end{array}$ & $\begin{array}{c}\text { Lianyungang City of Jiangsu } \\
\text { Province }\end{array}$ \\
\hline LA17-18 & $\begin{array}{l}\text { Lemna } \\
\text { aequinoctialis }\end{array}$ & Linyi City of Shandong Province \\
\hline
\end{tabular}

communication bus module (CMB-20A), a vacuum degasser, binary gradient pumps (LC-30AD), an autosampler (SIL-30A), and a column oven (CTO-30A) coupled with an AB Sciex QTRAP 5500 (AB SCIEX, USA). A Waters XBridge Amide column $(2.1 \mathrm{~mm} \times 150 \mathrm{~mm}, 2.5 \mu \mathrm{m}$, Waters, USA) was used for chromatographic separation. The binary mobile phase was composed of acetonitrile (A) and $10 \mathrm{mM}$ ammonium formate with $0.2 \%(\mathrm{v} / \mathrm{v})$ formic acid (B) at a flow rate of $0.4 \mathrm{~mL} / \mathrm{min}$. The linear gradient elution was carried out as follows: $0-5 \mathrm{~min}, 90 \%-85.5 \% \mathrm{~A}$; 5-11 $\mathrm{min}, 85.5 \%-$ $54 \% \mathrm{~A} ; 11-12 \mathrm{~min}, 54 \%-10 \%$ A; $12-14 \mathrm{~min}, 10 \% \mathrm{~A} ; 14-$ $15 \mathrm{~min}, 10 \%-90 \% \mathrm{~A} ; 15-20 \mathrm{~min}$, and $90 \% \mathrm{~A}$. The reequilibration time was $4 \mathrm{~min}$ with a total running time of $20 \mathrm{~min}$. The column compartment was kept at $20^{\circ} \mathrm{C}$, while the autosampler trial was maintained at $15^{\circ} \mathrm{C}$, and injection volume was $2 \mu \mathrm{l}$. The needle was washed with mixtures of acetonitrile and water.

The mass spectrometry assay was performed on a triple quadruple mass spectrometer equipped with an electrospray ionization source. The spectra were recorded under positiveion type with the multiple reaction monitoring (MRM) mode. The capillary voltage was $5500 \mathrm{~V}$, and desolvation gas temperature was $550^{\circ} \mathrm{C}$. The curtain gas was 35 psi with both nebulizer and drying gas of 55 psi. Nitrogen was used as source gas with purity more than $95 \%$ and collision gas with purity over $99.999 \%$. The 24 components of amino acids were optimized in the tuning mode with mass only to obtain the mass of the precursor and product ion, the best declustering potential (DP), and collision energy (CE), respectively. The details are shown in Table 2. The entrance potential (EP) and collision cell exit potential (CXP) were set as default value. The typical LC-QTRAP-MS/MS chromatograms are shown in Figure 1. 
TABLE 2: The precursor ions, product ions, declustering potential, and collision energy of amino acids.

\begin{tabular}{lccccc}
\hline Number & Compound & $\begin{array}{c}\text { Precursor } \\
\text { ion }\end{array}$ & $\begin{array}{c}\text { Product } \\
\text { ion }\end{array}$ & $\begin{array}{c}\text { DP } \\
(\mathrm{V})\end{array}$ & $\begin{array}{c}\text { CE } \\
(\mathrm{V})\end{array}$ \\
\hline 1 & Tyr & 182.0 & 91.1 & 60 & 37 \\
2 & Ala & 90.0 & 44.1 & 50 & 14 \\
3 & Glu & 148.1 & 84.0 & 60 & 21 \\
4 & Phe & 166.1 & 120.1 & 60 & 19 \\
5 & His & 156.1 & 110.3 & 80 & 20 \\
6 & Ile & 132.1 & 86.1 & 50 & 14 \\
7 & Asp & 134.1 & 74.0 & 50 & 19 \\
8 & Lys & 147.0 & 84.1 & 60 & 23 \\
9 & Gly & 76.1 & 29.9 & 40 & 16 \\
10 & Val & 118.1 & 71.9 & 50 & 15 \\
11 & Cit & 176.2 & 70.0 & 60 & 31 \\
12 & GABA & 104.1 & 86.8 & 50 & 14 \\
13 & Cys2 & 241.1 & 73.9 & 80 & 40 \\
14 & Pro & 116.0 & 70.1 & 60 & 22 \\
15 & Trp & 205.1 & 146.0 & 50 & 24 \\
16 & Leu & 132.1 & 86.1 & 50 & 14 \\
17 & Arg & 175.2 & 70.2 & 90 & 30 \\
18 & Cys & 122.1 & 59.0 & 40 & 32 \\
19 & Hpro & 132.1 & 86.1 & 60 & 20 \\
20 & Met & 150.1 & 103.9 & 60 & 14 \\
21 & Thr & 120.1 & 74.1 & 40 & 14 \\
22 & Asn & 133.1 & 74.0 & 60 & 21 \\
23 & Gln & 147.0 & 84.1 & 60 & 23 \\
24 & Ser & 106.0 & 60.1 & 60 & 15 \\
\hline
\end{tabular}

2.3. Preparation of Reference Compound Solution. Stock solutions of individual standards were made by dissolving accurately weighed components in $0.5 \%$ formic acid at a concentration of $0.2 \mathrm{mg} / \mathrm{mL}$ approximately and stored at $4^{\circ} \mathrm{C}$ before use. The mixed working solutions of all the standards were diluted with $0.5 \%$ formic acid solution to a series of appropriate concentrations immediately before analysis and used to attain the calibration curves.

2.4. Preparation of Sample Solution. Each sample powder was weighed $0.2 \mathrm{~g}$ accurately and transferred into a $25 \mathrm{~mL}$ stainless tube with 6 stainless beads with a diameter of $0.6 \mathrm{~mm}$. Then, the sample was extracted in a highthroughput tissue-grinding apparatus with vibrating frequency of $70 \mathrm{kHz}$ for $120 \mathrm{~s}$ with $15 \mathrm{~mL} 0.5 \%$ formic acid. The sample solution was centrifuged at $15000 \mathrm{rpm}$ for $10 \mathrm{~min}$, and then the supernatant was screened through a $0.22 \mu \mathrm{m}$ polytetrafluoroethylene membrane filter and stored in a glass bottle at $4^{\circ} \mathrm{C}$ for later LC-MS/MS analysis.

2.5. Method Validation. For each reference substance, the calibration curve was confirmed by linear regression of the peak area versus concentration. The limits of detection (LOD) and limits of quantification (LOQ) were determined by diluting the standard solution till the signal-to-noise ratios were about 3 and 10, respectively. Precision was determined by intraday and interday variability. The intraday variability was conducted by determining the same standard solution in six replicates on the same day. The interday variability was conducted by determining the same solution for three consecutive days. The relative standard deviation (RSD) values were calculated to denote the precision. Stability of the sample solution was analysed by peak areas of analytes at 0,2 , $4,8,12$, and $24 \mathrm{~h}$ at room temperature. To evaluate the repeatability of the developed method, the same sample was analysed in six replicates and variations were expressed as RSD. The recovery test was performed to assess the accuracy of the method. For the test, a known amount of the 24 standard components was spiked into a certain amount $(0.1 \mathrm{~g})$ of sample. Then, the spiked sample was extracted and analysed as described. The recovery rate was calculated by using the following formula: recovery $(\%)=$ (measured amount original amount)/spiked amount $\times 100 \%$. Six replicates were performed for the recovery test.

2.6. Data Analysis. The quantitative analyses of acquired data were processed by MultiQuant 3.0.2 (AB SCIEX, USA). Multivariate statistical analysis including PCA and OPLSDA was used to classify the sample. SIMCA-P 14.1 (Umetrics $A B$, Sweden) was used to perform statistical analysis for the data of 59 batches of duckweed.

2.7. Analysis of Minerals and Total Proteins. Twenty-four minerals of each environment water where duckweed lived were quantified by ICP-MS. Total nitrogen and phosphorus of the water body were measured according to the alkaline potassium persulfate digestion method GB11894-89 and the ammonium molybdate spectrophotometric method GB1189389 published by the State Bureau of Technological Supervision of China. Total proteins of each duckweed were determined by the Kjeldahl method. Each sample of duckweeds was hydrolyzed in acidic conditions, and then total amino acids were quantified by the HPLC-MSMS method mentioned above.

\section{Results and Discussion}

3.1. Optimization of Extraction Procedure. Free amino acids can dissolve in methanol, ethanol, water, diluted acid, and so on. In order to acquire an efficient extraction strategy of amino acids from duckweed, variables of the extraction process were investigated. The solvents (methanol, ethanol, water, $0.1 \%$ formic acid, and $0.5 \%$ formic acid), methods (heating reflux, ultrasonication, and tissue-grinding), and time $(20,30$, and $40 \mathrm{~min}$ for ultrasonication; 60,90 , and $120 \mathrm{~s}$ for tissue-grinding) were studied. The results showed that the amount of amino acids had no significant difference between the ultrasonication time of $30 \mathrm{~min}$ in $0.5 \%$ formic acid and tissue-grinding time of $120 \mathrm{~s}$ in $0.5 \%$ formic acid. The amounts of extraction by other methods were not more than that by these two modalities. From the viewpoint of working efficiency, the tissue-grinding method was much more time-saving than the ultrasonication method by the extracting time of $120 \mathrm{~s}$ versus $30 \mathrm{~min}$.

3.2. Optimization of UPLC Condition. Chromatographic conditions were optimized to attain a satisfactory separation for amino acid especially for isomeric molecules. Columns 


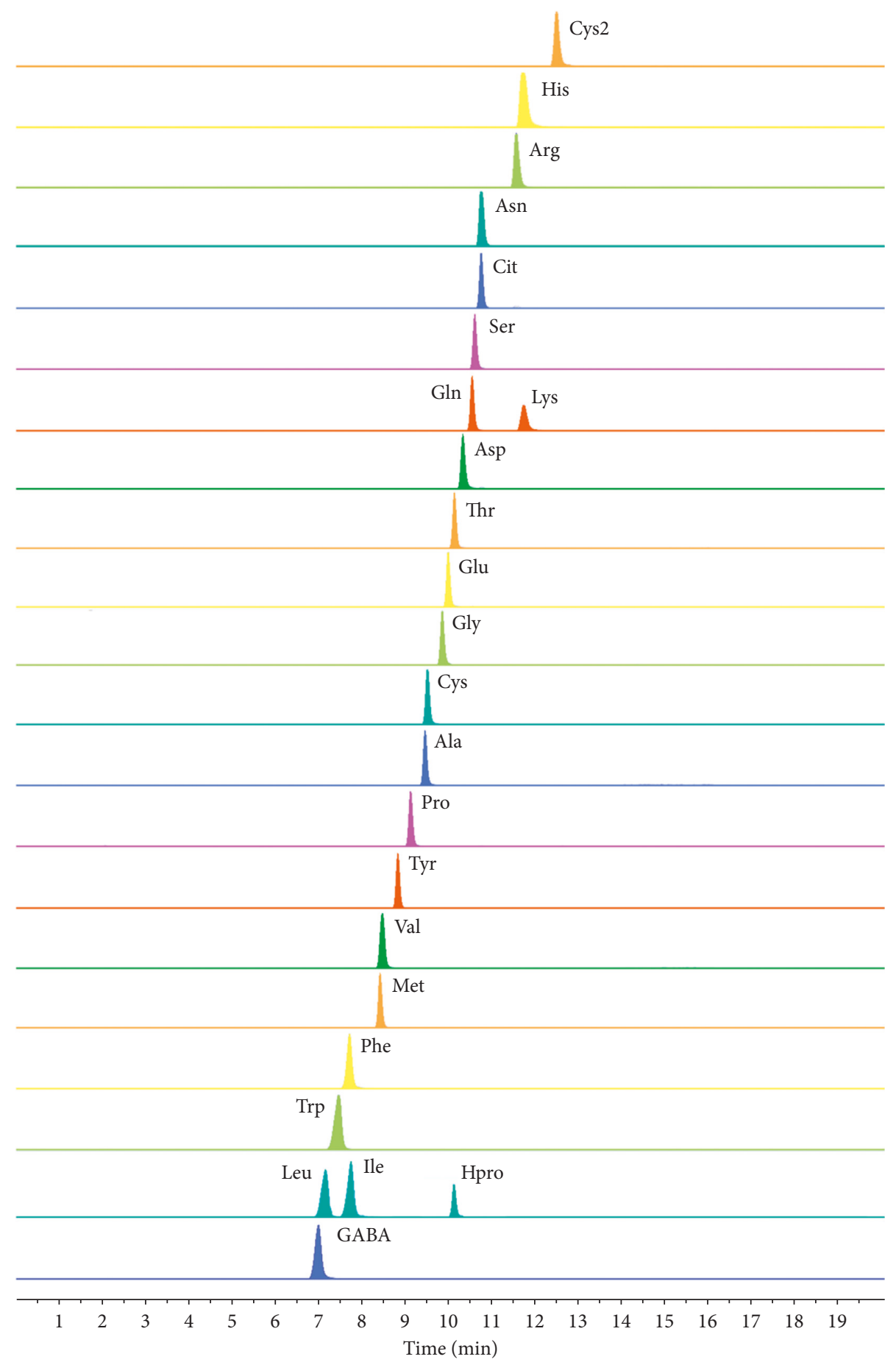

Figure 1: Typical MRM chromatograms of the 24 amino acids.

(Waters XBridge Amide, $2.5 \mu \mathrm{m}, 2.1 \times 150 \mathrm{~mm}$ and Agilent Poroshell 120 HILIC, $2.7 \mu \mathrm{m}, 2.1 \times 150 \mathrm{~mm}$ ), column temperature $\left(20,25,30,35\right.$, and $\left.40^{\circ} \mathrm{C}\right)$, mobile phase (acetonitrile- $0.1 \%$ formic acid, acetonitrile- $0.2 \%$ formic acid, acetonitrile with $0.2 \%$ formic acid- $0.2 \%$ formic acid, and acetonitrile- $10 \mathrm{mM}$ ammonium formate with $0.2 \%$ formic acid), and different kinds of gradient elution were investigated.

The results demonstrated that the peak shape of amino acids became good when the concentration of formic acid rose, but retention time would be shortened significantly especially if some formic acid was complemented into the acetonitrile. The buffers such as ammonium formate increased the resolution degrees of amino acids. Better retention times and separations were observed by conducting analysis on Waters Amide column than on Agilent Poroshell 120 HILIC column, and the best chromatograms were gained with temperature controlled at $20^{\circ} \mathrm{C}$. Especially for the isomers of leucine and isoleucine, baseline separation was 
TABLe 3: Calibration curves, LODs, and LOQs for the 24 compounds.

\begin{tabular}{|c|c|c|c|c|c|c|}
\hline Number & Compound & Calibration curve & $R^{2}$ & Linear range $(\mathrm{ng} / \mathrm{mL})$ & LOQ (ng/mL) & $\mathrm{LOD}(\mathrm{ng} / \mathrm{mL})$ \\
\hline 1 & Tyr & $y=6534.1 x+6063.4$ & 0.9984 & $1.16-5780$ & 0.92 & 0.46 \\
\hline 2 & Ala & $y=7168.9 x+4932.8$ & 0.9969 & $5.30-5300$ & 3.71 & 1.24 \\
\hline 3 & Glu & $y=12796 x+47334$ & 0.9960 & $6.41-2564$ & 4.49 & 1.50 \\
\hline 4 & Phe & $y=59157 x+42917$ & 0.9965 & $0.99-992.0$ & 0.79 & 0.40 \\
\hline 5 & His & $y=20263 x+247917$ & 0.9962 & $5.57-5570$ & 3.90 & 1.30 \\
\hline 6 & Ile & $y=70857 x+46587$ & 0.9957 & $1.07-1074$ & 0.86 & 0.43 \\
\hline 7 & Asp & $y=7084.7 x+86152$ & 0.9963 & $5.43-5430$ & 3.80 & 1.27 \\
\hline 8 & Lys & $y=4305.1 x+17648$ & 0.9980 & $5.53-5530$ & 3.87 & 1.94 \\
\hline 9 & Gly & $y=1063.0 x+3407.3$ & 0.9990 & $0.94-4680$ & 0.75 & 0.37 \\
\hline 10 & Val & $y=31972 x+35728$ & 0.9962 & $1.11-1112$ & 0.89 & 0.44 \\
\hline 11 & Cit & $y=8520.8 x+9811.0$ & 0.9980 & $1.01-5070$ & 0.81 & 0.41 \\
\hline 12 & GABA & $y=18495 x+14623$ & 0.9981 & $1.10-5490$ & 0.88 & 0.44 \\
\hline 13 & Cys2 & $y=2389.7 x+3146.6$ & 0.9978 & $1.09-5440$ & 0.87 & 0.44 \\
\hline 14 & Pro & $y=51204 x+58539$ & 0.9981 & $1.02-510.0$ & 0.82 & 0.41 \\
\hline 15 & $\operatorname{Trp}$ & $y=19030 x+4465.3$ & 0.9977 & $1.24-2476$ & 0.99 & 0.50 \\
\hline 16 & Leu & $y=56715 x+40047$ & 0.9974 & $1.01-1012$ & 0.81 & 0.40 \\
\hline 17 & Arg & $y=11505 x+84828$ & 0.9974 & $5.96-5960$ & 4.17 & 1.39 \\
\hline 18 & Cys & $y=2496.6 x+1017.5$ & 0.9988 & $1.20-6012$ & 0.96 & 0.48 \\
\hline 19 & Hpro & $y=15783 x+3968.1$ & 0.9977 & $0.95-1892$ & 0.76 & 0.38 \\
\hline 20 & Met & $y=8626.4 x+1545.9$ & 0.9984 & $1.05-5250$ & 0.84 & 0.42 \\
\hline 21 & Thr & $y=8807.8 x+19073$ & 0.9957 & $4.46-4460$ & 3.12 & 1.56 \\
\hline 22 & Asn & $y=4939.9 x+22367$ & 0.9967 & $1.20-5980$ & 0.96 & 0.48 \\
\hline 23 & $G \ln$ & $y=7733.9 x+8338.4$ & 0.9961 & $0.93-4650$ & 0.74 & 0.37 \\
\hline 24 & Ser & $y=7731.3 x+54859$ & 0.9977 & $5.09-5090$ & 3.56 & 1.19 \\
\hline
\end{tabular}

TABle 4: Precision, stability, repeatability, and accuracy of the investigated analytes $(n=6)$.

\begin{tabular}{|c|c|c|c|c|c|c|c|}
\hline \multirow{2}{*}{ Number } & \multirow{2}{*}{ Compound } & \multicolumn{2}{|c|}{ Precision } & \multirow{2}{*}{$\begin{array}{l}\text { Stability } \\
\text { RSD (\%) }\end{array}$} & \multirow{2}{*}{$\begin{array}{l}\text { Repeatability } \\
\text { RSD (\%) }\end{array}$} & \multicolumn{2}{|c|}{ Accuracy } \\
\hline & & Intraday RSD (\%) & Interday RSD (\%) & & & Recovery (\%) & RSD (\%) \\
\hline 1 & Tyr & 1.36 & 1.85 & 0.94 & 3.05 & 98.56 & 1.33 \\
\hline 2 & Ala & 2.60 & 3.31 & 3.47 & 3.09 & 102.49 & 2.18 \\
\hline 3 & Glu & 2.07 & 2.56 & 2.10 & 2.11 & 106.94 & 3.76 \\
\hline 4 & Phe & 0.66 & 1.03 & 2.60 & 1.66 & 97.23 & 4.03 \\
\hline 5 & His & 1.07 & 3.30 & 1.58 & 1.17 & 98.32 & 2.20 \\
\hline 6 & Ile & 0.97 & 3.21 & 3.82 & 0.71 & 99.09 & 3.57 \\
\hline 7 & Asp & 1.96 & 3.98 & 2.42 & 1.84 & 97.86 & 2.36 \\
\hline 8 & Lys & 2.70 & 3.51 & 1.44 & 0.99 & 102.30 & 3.02 \\
\hline 9 & Gly & 1.66 & 2.65 & 3.43 & 3.74 & 104.48 & 3.07 \\
\hline 10 & Val & 2.42 & 2.89 & 3.30 & 0.83 & 107.51 & 1.52 \\
\hline 11 & Cit & 1.47 & 1.88 & 3.12 & 3.86 & 99.14 & 2.21 \\
\hline 12 & GABA & 3.14 & 2.32 & 2.27 & 0.82 & 102.54 & 3.41 \\
\hline 13 & Cys2 & 2.53 & 4.27 & 3.24 & 1.49 & 96.60 & 1.27 \\
\hline 14 & Pro & 1.21 & 3.39 & 1.09 & 2.09 & 101.94 & 3.20 \\
\hline 15 & Trp & 0.37 & 3.93 & 1.36 & 1.39 & 99.11 & 3.46 \\
\hline 16 & Leu & 1.50 & 3.90 & 3.40 & 1.50 & 95.27 & 3.61 \\
\hline 17 & Arg & 2.72 & 4.15 & 3.72 & 1.45 & 102.37 & 1.79 \\
\hline 18 & Cys & 2.82 & 3.63 & 1.16 & 0.53 & 103.65 & 3.82 \\
\hline 19 & Hpro & 3.05 & 2.23 & 0.87 & 2.38 & 97.55 & 3.91 \\
\hline 20 & Met & 1.57 & 3.02 & 1.26 & 0.52 & 104.89 & 2.14 \\
\hline 21 & Thr & 2.11 & 2.13 & 1.77 & 3.01 & 95.97 & 3.00 \\
\hline 22 & Asn & 2.93 & 2.85 & 1.48 & 3.68 & 105.35 & 2.95 \\
\hline 23 & Gln & 0.97 & 1.87 & 1.22 & 2.72 & 102.33 & 2.16 \\
\hline 24 & Ser & 2.71 & 2.86 & 0.98 & 1.48 & 97.44 & 1.88 \\
\hline
\end{tabular}

successfully achieved when using the mobile phase consisting of acetonitrile- $10 \mathrm{mM}$ ammonium formate with $0.2 \%$ formic acid. Under other abovementioned conditions, these two isomeric amino acids were not well separated reciprocally.
3.3. Optimization of MS/MS Conditions. Primary experiments were conducted to acquire the best mass spectrometry conditions of amino acids individually. For this purpose, each reference component of amino acids with the concentration of approximate $100 \mathrm{ng} / \mathrm{mL}$ was delivered into the 


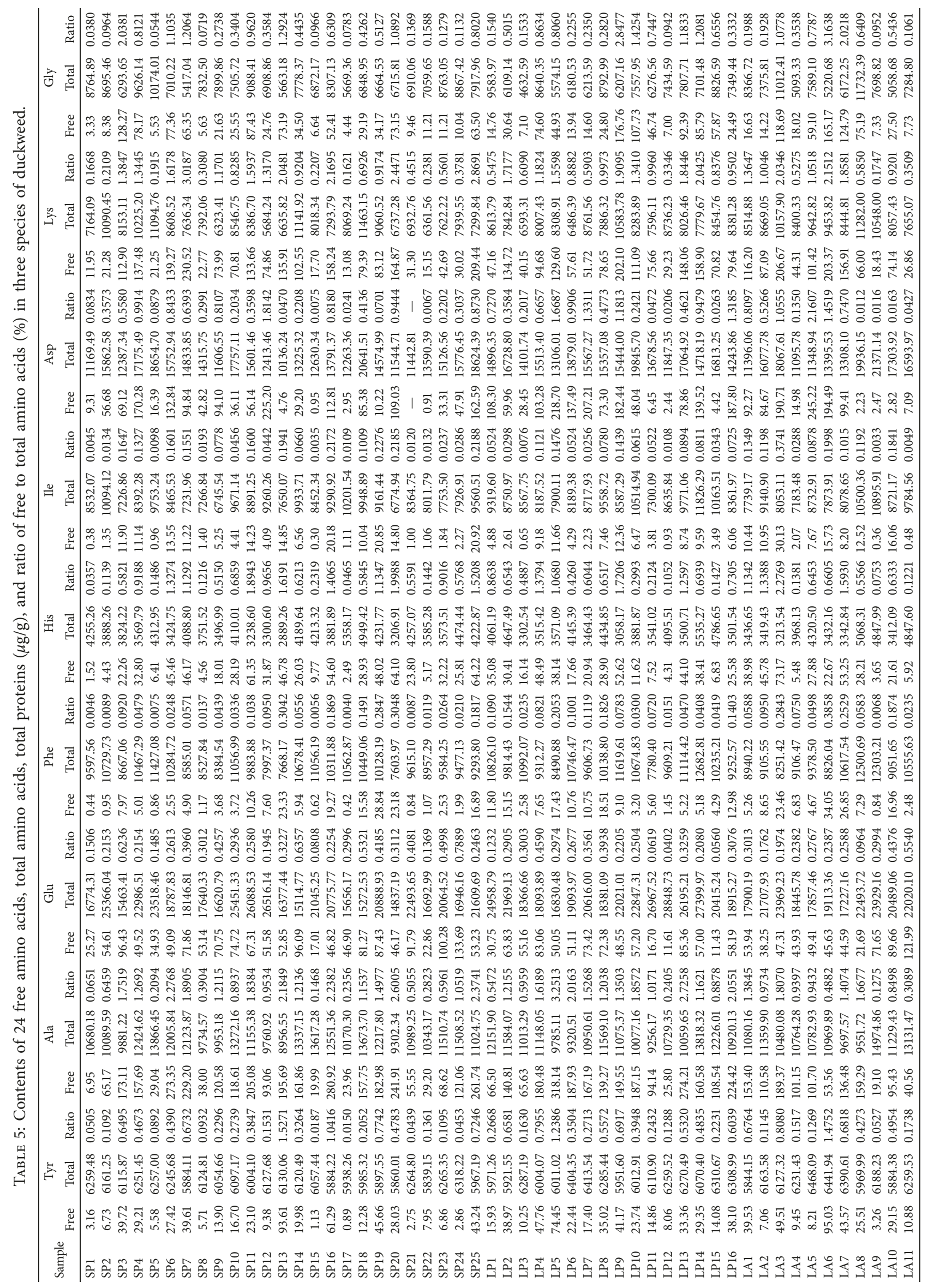




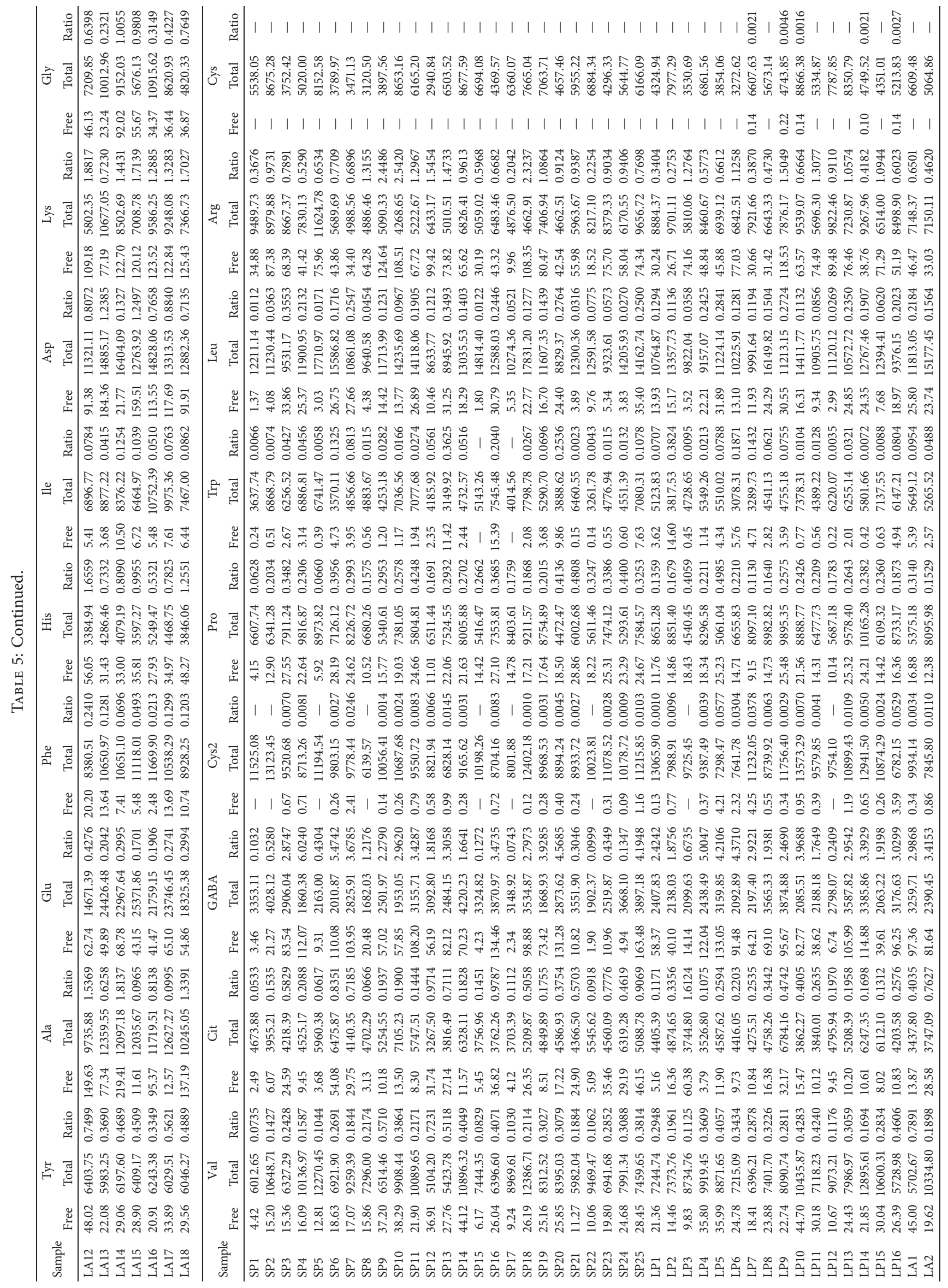




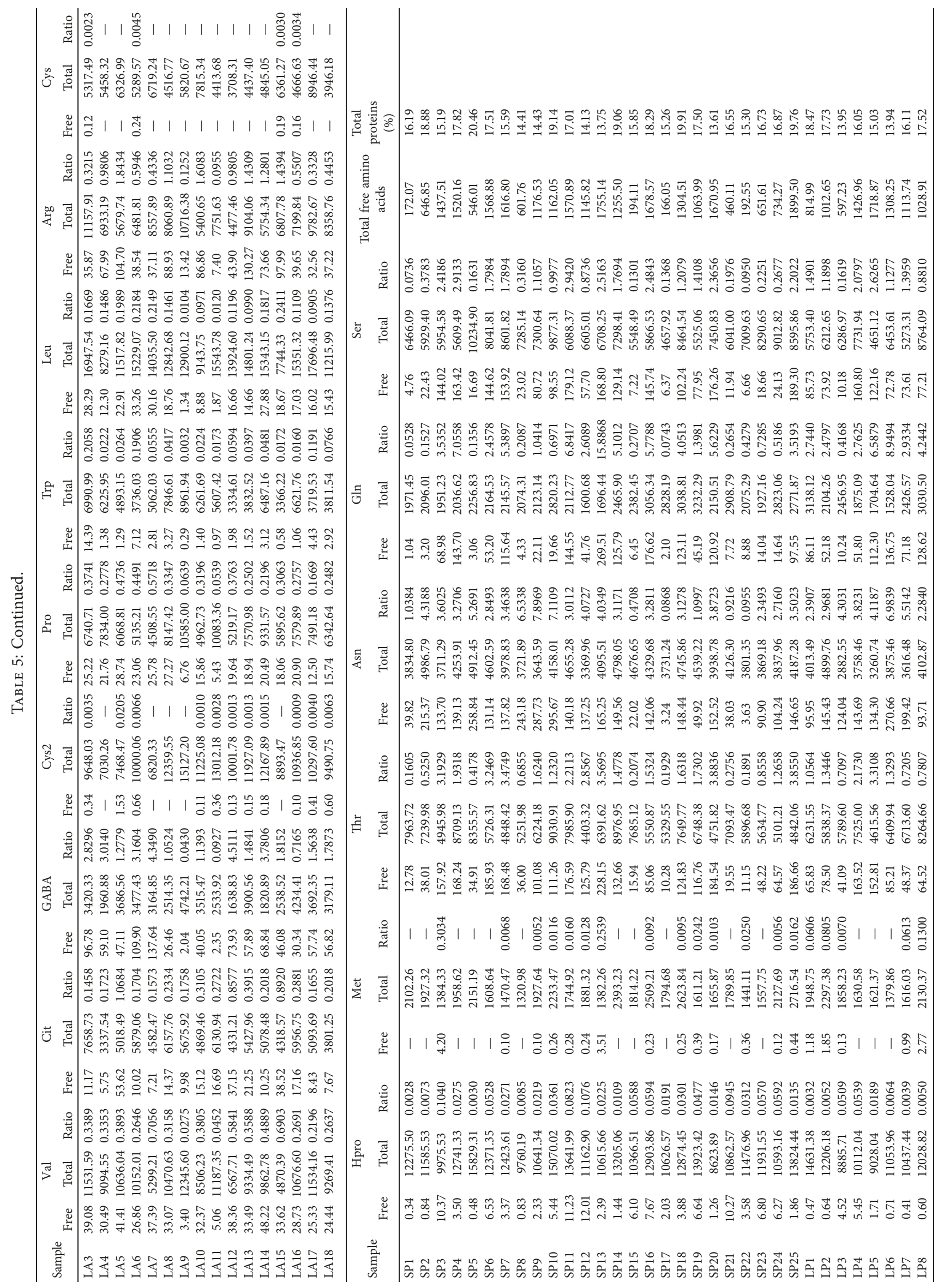




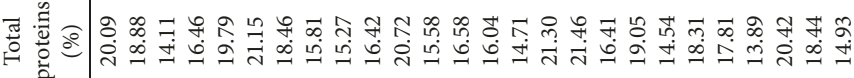
悬

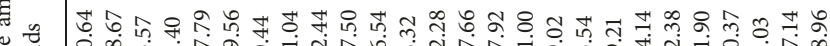

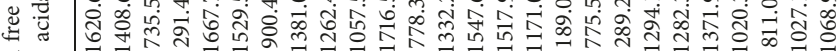
宽

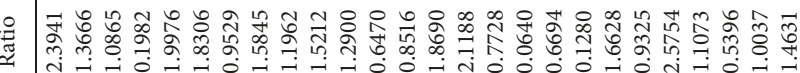

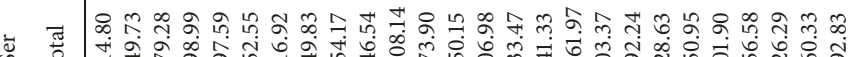

ڤ

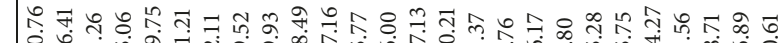
东

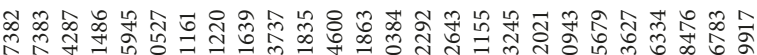

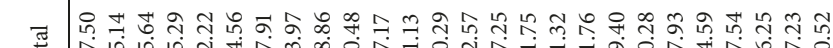

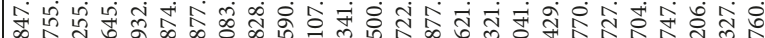

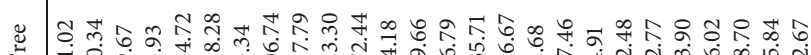

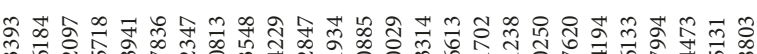

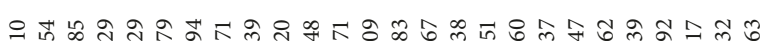

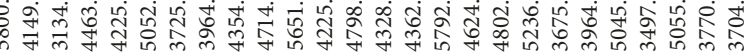

\&

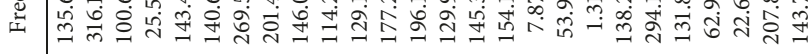

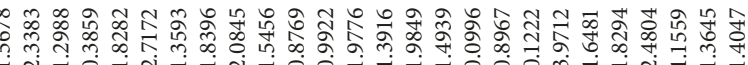

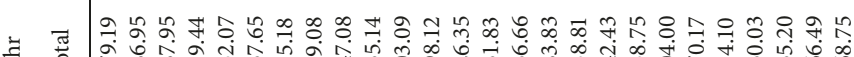
刍 等

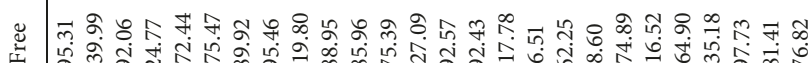

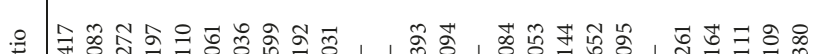

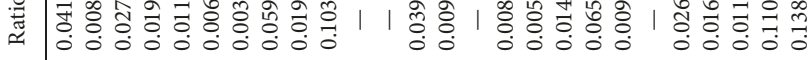
च च ¿

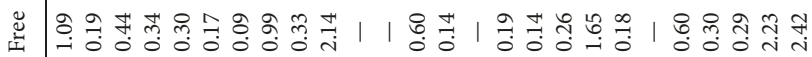

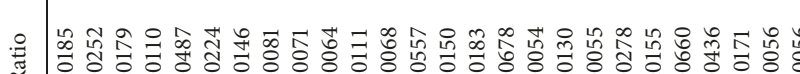
«

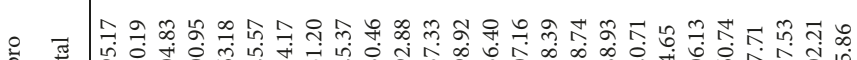
商 晋 产

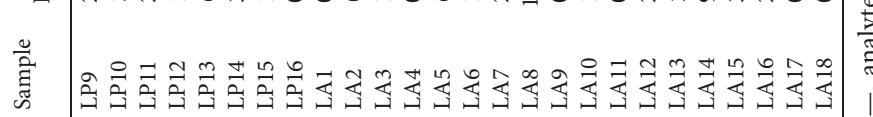




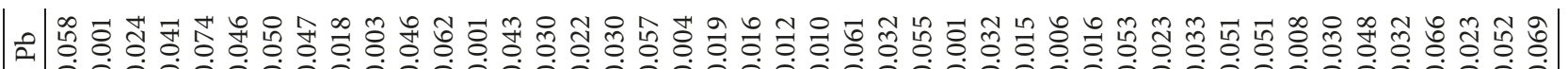

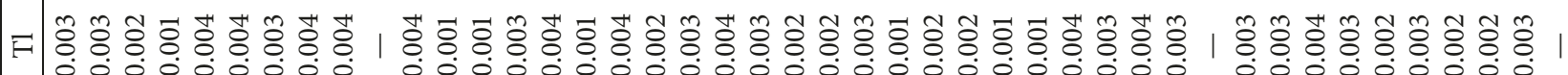

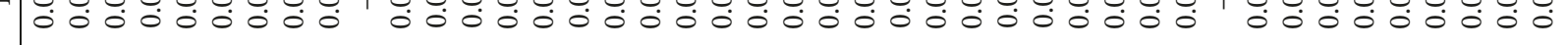

운

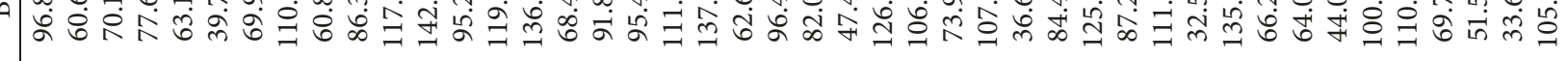

क ॠ

ઈี

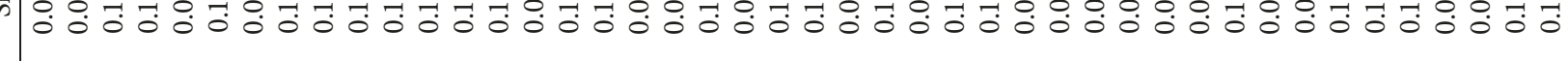

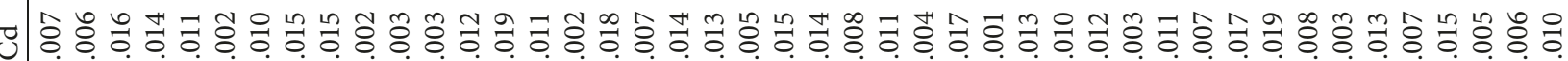
ठृ

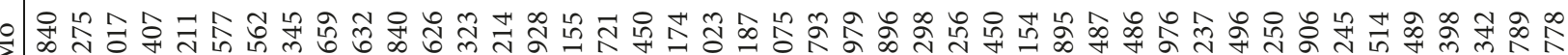

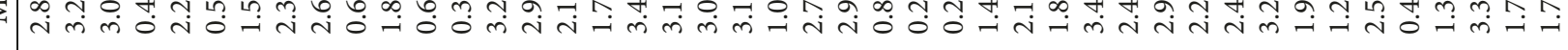

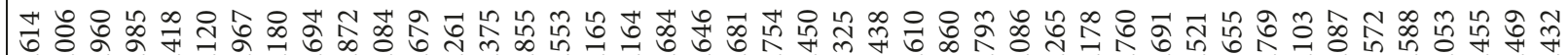

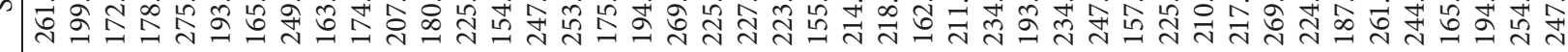

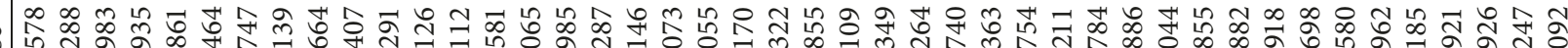

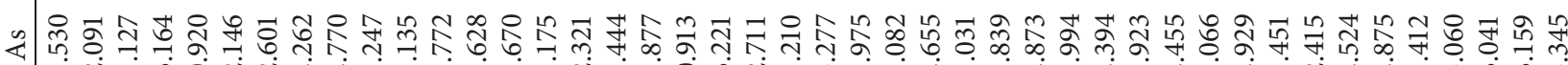
隹

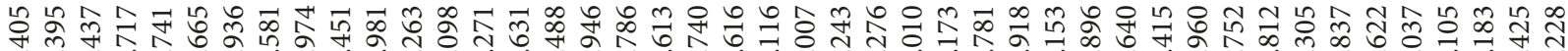
बें

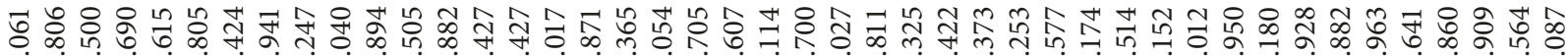

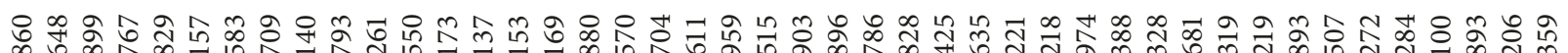

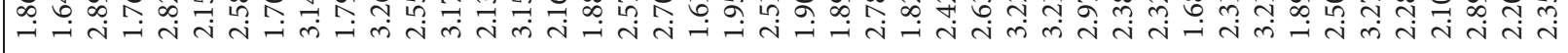

○

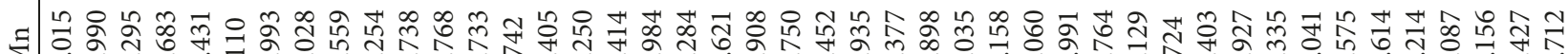

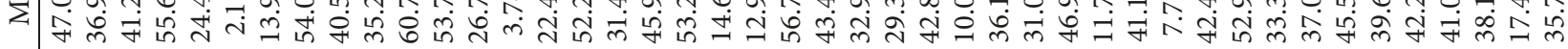

ఛ

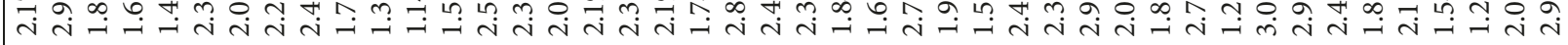

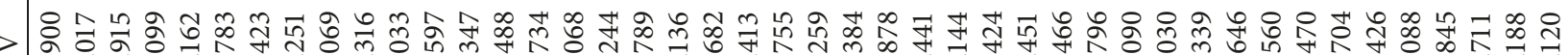
i

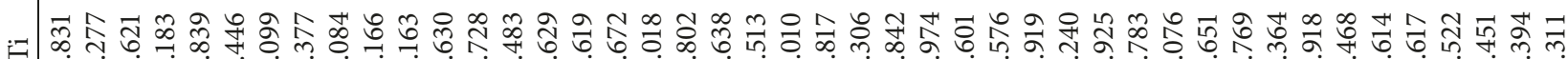
त त 


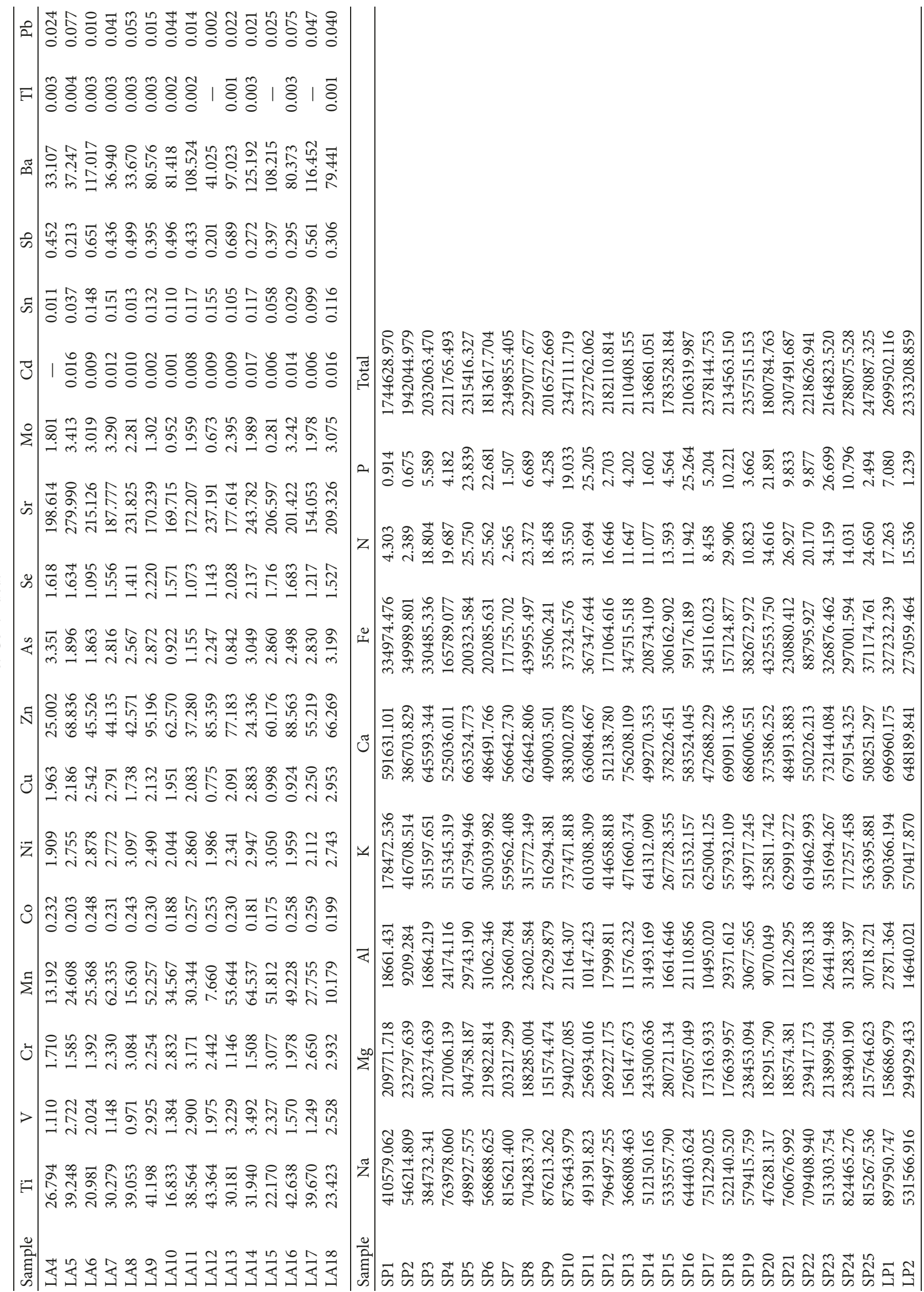




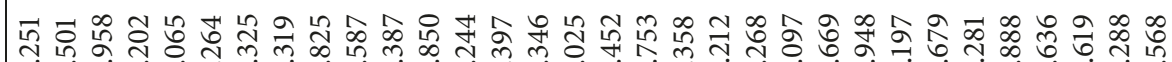

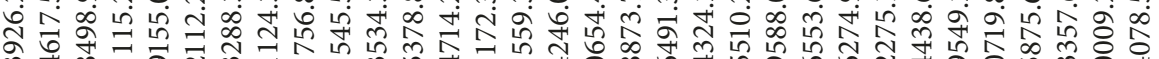

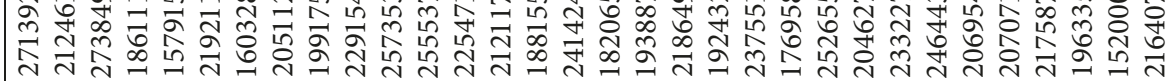

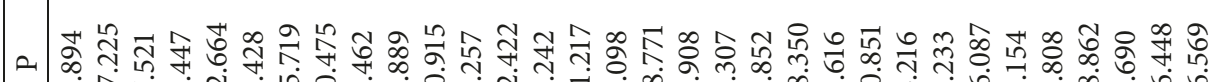
品资

mे

ㄴํㅇ

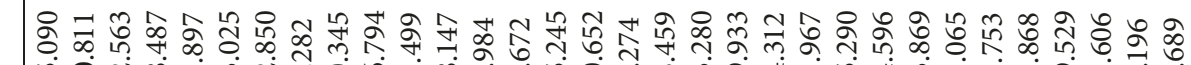

许 m

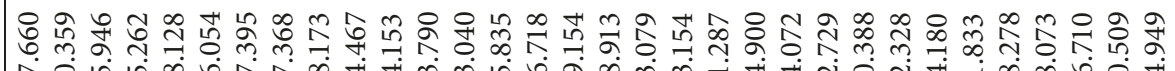
ง

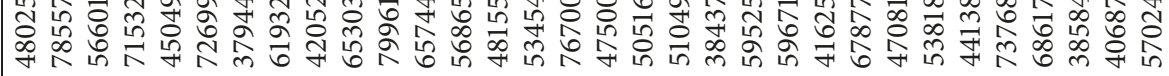

स ฟ

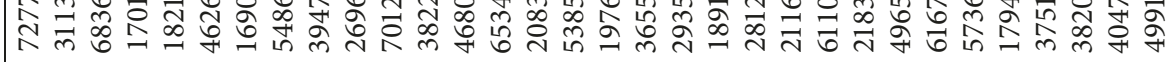

क

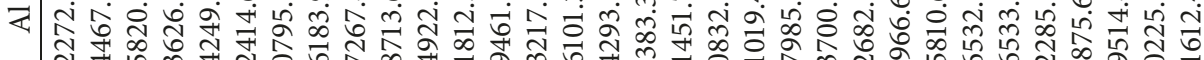

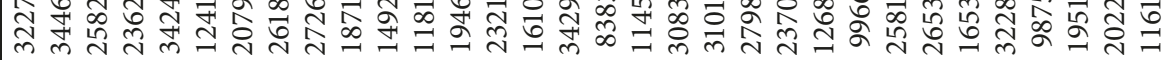

年

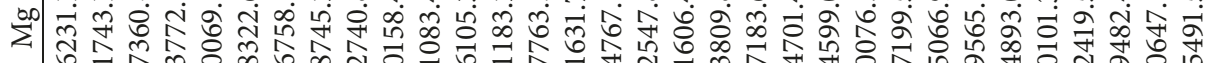

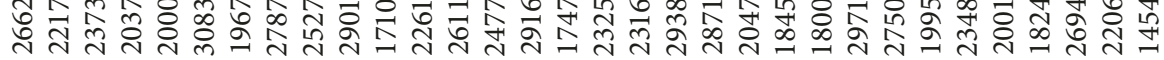

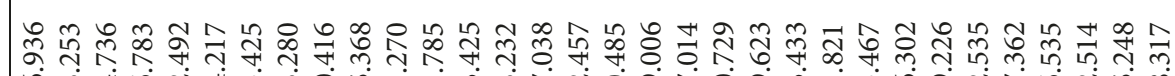
z

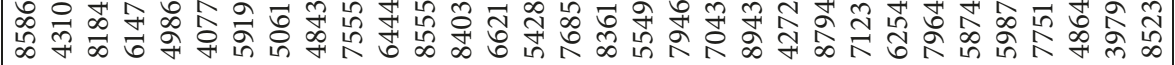

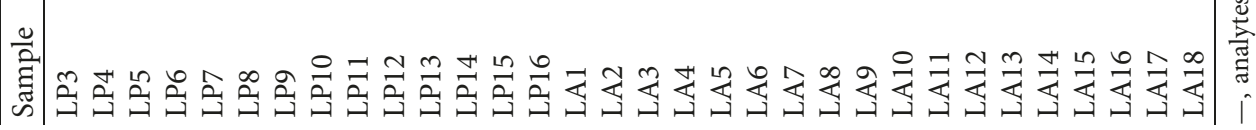


mass spectrometer directly via a syringe pump with the velocity of $7 \mu \mathrm{L} / \mathrm{min}$. While tuning the standard dissolved in water, most response of amino acids was very low when the sodium-adducted ion, $[\mathrm{M}+\mathrm{Na}]^{+}$, was relatively high. On the contrary, when dissolving the standard in $0.1 \%$ or higher concentration of formic acid solution, the response of protonated molecule, $[\mathrm{M}+\mathrm{H}]^{+}$, was dramatically higher and the metal-adducted ion was barely observed. Consequently, precursor ion $(\mathrm{Q} 1)$, product ion $(\mathrm{Q} 3)$, declustering potential (DP), and collision energy (CE) of each amino acid were acquired and optimized.

3.4. Method Validation. As shown in Table 3, the calibration curves of twenty-four amino acids showed good linear regression (all correlation coefficients $>0.995$ ) within a wide range of concentration. The LOD and LOQ of each analyte with the signal-to-noise ratio $(\mathrm{S} / \mathrm{N})$ of 3 and 10 were in the range of $0.37-1.94 \mathrm{ng} / \mathrm{mL}$ and $0.74-4.49 \mathrm{ng} / \mathrm{mL}$, respectively. The RSD values of intraday and interday precision are summarized in Table 4. From the results, the present method was found to be precise with intraday variability less than $3.14 \%$ and interday variability less than $4.27 \%$. The sample solutions were stable within $24 \mathrm{~h}$ with stability RSD $<3.82 \%$. The RSD values of repeatability were $0.52 \%-3.86 \%$. The recoveries of 24 amino acids ranged from $95.27 \%-107.51 \%$ with RSD $<4.03 \%$.

3.5. Quantitative Analysis for Samples. The developed UPLC-MS/MS method was applied for simultaneous determination of 24 free amino acids in 59 batches of three species of duckweed. All the contents are displayed in Table 5. The results showed that the total amount of amino acids varied dramatically among each sample from different regions and species. Total content of AAs in SP25 from Baoding City of Hebei Province reached as high as $1899.50 \mu \mathrm{g} / \mathrm{g}$, which was much more than that in SP17 of $166.05 \mu \mathrm{g} / \mathrm{g}$ from Lianyungang City of Jiangsu Province. For each amino acid, the content also varied significantly even in the same sample. Coincidentally, the contents of free amino acids that include sulfur in their molecules were much less than others, including cysteine, cystine, and methionine with the concentration of $0.24,4.25$, and $4.20 \mu \mathrm{g} / \mathrm{g}$ in maximum, respectively. Especially for cysteine, it was not found in all of Spirodela polyrhiza and only detected in several samples of other two species. The putative reason was that the thiol in cysteine was not stable and easily oxidized. But in general, there was no significant difference observed in the total content of all FAAs among different species.

Twenty-six minerals, total proteins, and the content of amino acids after hydrolysis are shown in Tables 5 and 6 . From the tables, it could be found that the total protein contents in 59 samples ranged from $13.61 \%$ to $21.46 \%$. The relative contents of amino acids such as Lys, Ala, Ser, Thr, GABA, Gln, and Asn were all a little higher than other components based on the average value of each species among three different varieties of duckweed. The contents of Cys, Cys2, and Met were higher after hydrolysis. Obviously, it could be seen that the contents of free amino acids in duckweed were much lower than that of protein-bound

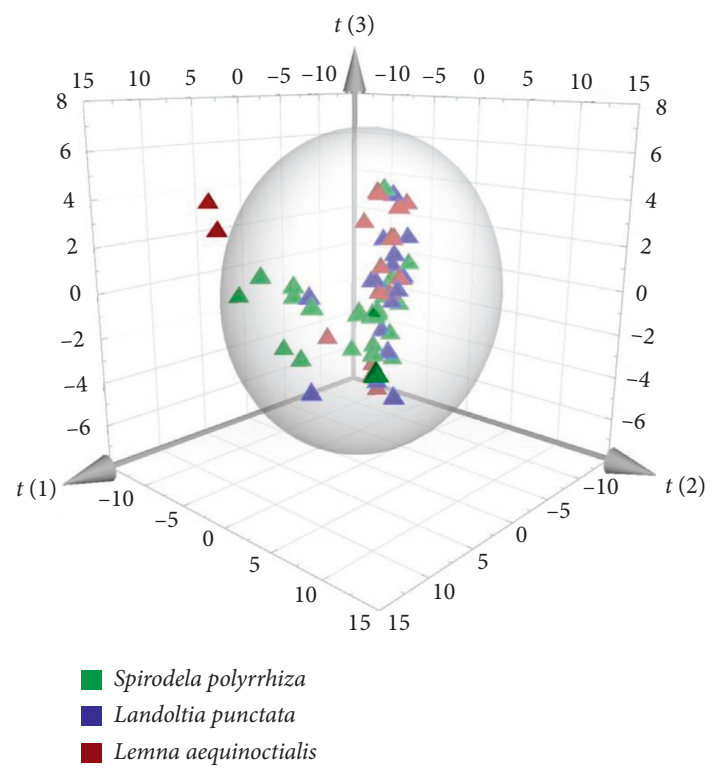

FIgURE 2: Three-dimensional score plot of principle component analysis (PCA) based on the content of free amino acids.

amino acids. Moreover, the data showed that the contents of free amino acids in duckweed were negatively correlated with binding amino acids.

The elements with higher content in the samples were sodium, calcium, potassium, iron, magnesium, and aluminum. Their concentration ranges were 366808.463-897950.747, 373586.252-799614.153, 169080.807-737471.818, 35506.241439955.497, 145491.528-308322.609, and 8383.317-34467.794 $\mu \mathrm{g} / \mathrm{L}$, respectively. The concentration ranges of strontium, barium, zinc, manganese and titanium were 154.053-279.990, $32.520-142.280$, 22.616-95.305, 2.110-64.537, 16.833-45.839 $\mu \mathrm{g} / \mathrm{L}$. The concentrations of vanadium, chromium, cobalt, nickel, copper, arsenic, selenium, molybdenum, cadmium, tin, antimony, thallium, and lead are very low. It ranged from 0.0 to $3.492 \mu \mathrm{g} / \mathrm{L}$. Evidently, the contents of macroelements in the samples were higher while they contained much lower trace elements.

3.6. Statistical Analysis. As one of the most important multivariate analysis techniques, PCA was employed to evaluate the variation among three species of duckweed. PCA is an unsupervised pattern recognition method without prior information of the data set and retained maximum variance of multidimensional data while reducing its dimensionality into two- or three-dimension [29-31]. Furthermore, all of the data information about amino acids was subjected to a supervised method, OPLS-DA [32], to get more information about different duckweeds. All the raw data were processed by normalization and Pareto scaling (Par) before modeling. Three dimensions were established in both the PCA and OPLS-DA models based on the content of free amino acids and the ratio of free to total amino acids with R2X (cum) value of $0.628,0.596$ and $0.758,0.676$, respectively. As shown in Figures 2-5, both PCA and OPLSDA methods demonstrated that Spirodela polyrhiza, 


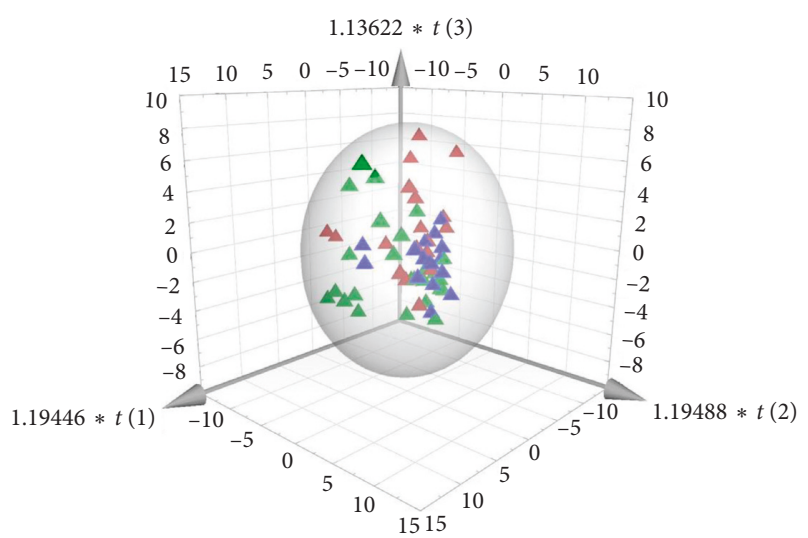

Spirodela polyrrhiza

Landoltia punctata

Lemna aequinoctialis

FIgURE 3: Three-dimensional score plot of orthogonal partial least square-discriminant analysis (OPLS-DA) based on the content of free amino acids.

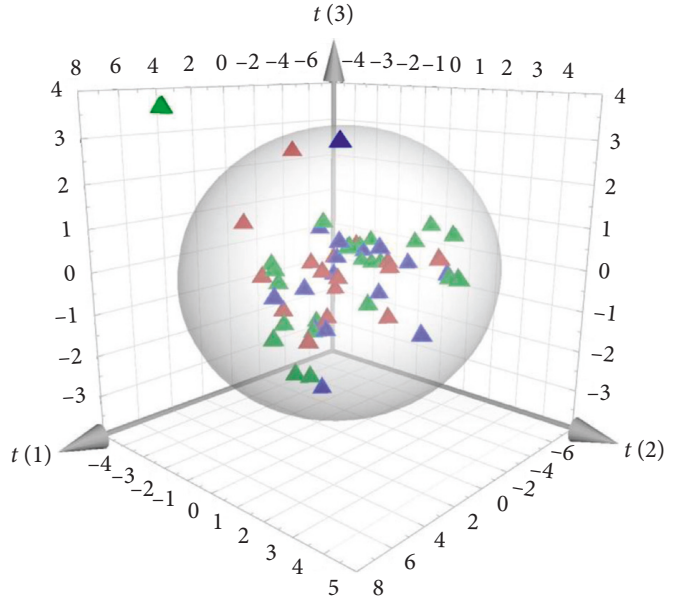

Spirodela polyrrhiza

Landoltia punctata

Lemna aequinoctialis

Figure 4: Three-dimensional score plot of principle component analysis (PCA) based on the ratio of free to total amino acids.

Landoltia punctata, and Lemna aequinoctialis were clustered together with each other in the score plot. There was no remarkable difference in different duckweeds.

\section{Conclusions}

In this study, a simple, fast, and convenient method with UPLC-QTRAP-MS/MS was established for the identification and quantification control of duckweeds by HILIC separation without derivatization. The results of method validation suggested that the developed method was sensitive, accurate, and precise for determination of 24 free amino acids. 59 batches of sample in three species were quantified, and then the data were statistically analysed by using PCA and OPLS-DA. The multivariate analysis

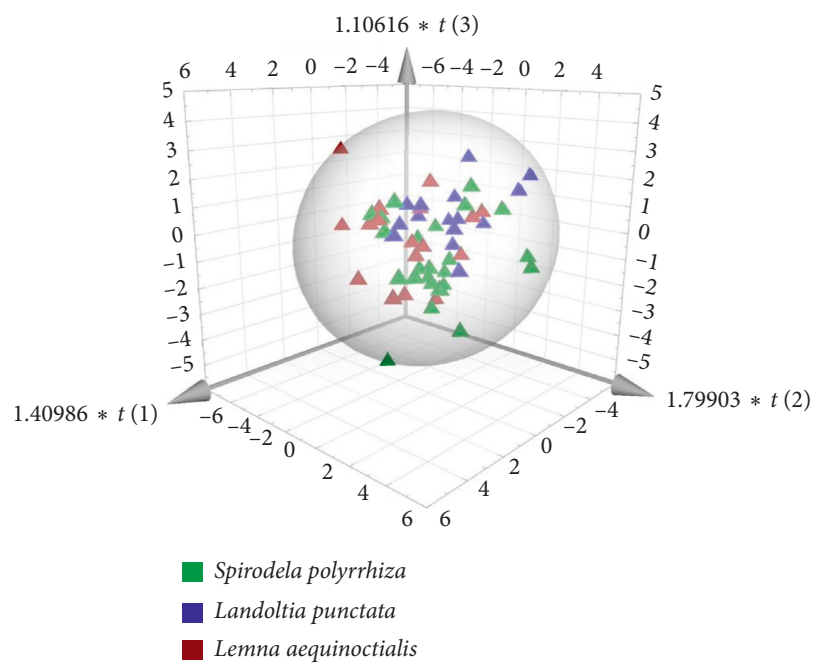

FIgURE 5: Three-dimensional score plot of orthogonal partial least squares-discriminant analysis (OPLS-DA) based on the ratio of free to total amino acids.

illustrated that the content of free amino acids was not significantly different among Spirodela polyrhiza, Landoltia punctata, and Lemna aequinoctialis in pattern recognition. But as a food, more amino acids mean more nutrition it has and more valuable it is. In other words, all of the three species of duckweed could be used as food equally if the absolute amount of AAs was more or less the same. In conclusion, a reliable and feasible method was developed for the nutritional evaluation of duckweeds.

\section{Data Availability}

The data used to support the findings of this study are included within the article.

\section{Conflicts of Interest}

The authors declare that there are no conflicts of interest regarding the publication of this paper.

\section{Acknowledgments}

This study was supported by the Chinese National Natural Science Foundation (81073002), the Program of Collaborative Innovation Center of Chinese Medicinal Material Resources Industrialization of Jiangsu Province (2016), and the National “Twentieth Five-Year" Technology Support Program (2011BAI04B06).

\section{References}

[1] E. Ernst and G. Legler, "The role of the hydroxy amino acid in the triplet sequence Asn-Xaa- $\mathrm{Thr}$ (Ser) for the N-glycosylation step during glycoprotein biosynthesis," Biochemical Journal, vol. 195, no. 3, pp. 639-644, 1981.

[2] C. P. S. Badenhorst, E. Erasmus, R. van der Sluis, C. Nortje, and A. A. van Dijk, "A new perspective on the importance of glycine conjugation in the metabolism of aromatic acids," Drug Metabolism Reviews, vol. 46, no. 3, pp. 343-361, 2014. 
[3] R. J. Ward, D. T. Dexter, and R. R. Crichton, "Neurodegenerative diseases and therapeutic strategies using iron chelators," Journal of Trace Elements in Medicine and Biology, vol. 31, pp. 267-273, 2015.

[4] G. Mondanelli, S. Ugel, U. Grohmann, and V. Bronte, "The immune regulation in cancer by the amino acid metabolizing enzymes ARG and IDO," Current Opinion in Pharmacology, vol. 35, pp. 30-39, 2017.

[5] P. J. Murray, "Amino acid auxotrophy as a system of immunological control nodes," Nature Immunology, vol. 17, no. 2, pp. 132-139, 2016.

[6] T. Themelis, R. Gotti, and R. Gatti, "A novel hydrophilic interaction liquid chromatography method for the determination of underivatized amino acids in alimentary supplements," Journal of Pharmaceutical and Biomedical Analysis, vol. 145, pp. 751-757, 2017.

[7] K. J. Appenroth, K. S. Sree, V. Bohm et al., "Nutritional value of duckweeds (Lemnaceae) as human food," Food Chemistry, vol. 217, pp. 266-273, 2017.

[8] P. Ziegler, K. Adelmann, S. Zimmer, C. Schmidt, and K. J. Appenroth, "Relative in vitro growth rates of duckweeds (Lemnaceae)-the most rapidly growing higher plants," Plant Biology, vol. 17, no. 1, pp. 33-41, 2015.

[9] M. F. A. de Beukelaar, G. G. Zeinstra, J. J. Mes, and A. R. H. Fischer, "Duckweed as human food. The influence of meal context and information on duckweed acceptability of Dutch consumers," Food Quality and Preference, vol. 71, pp. 76-86, 2019.

[10] J. P. Goopy and P. J. Murray, "A review on the role of duckweed in nutrient reclamation and as a source of animal feed," Asian-Australasian Journal of Animal Sciences, vol. 16, no. 2, pp. 297-305, 2003.

[11] K. E. Anderson, Z. Lowman, A. M. Stomp, and J. Chang, "Duckweed as a feed ingredient in laying hen diet and its effect on egg production and composition," International Journal of Poultry Science, vol. 10, no. 1, pp. 4-7, 2011.

[12] L. Landesman, C. Fedler, and R. Duan, "Plant nutrient phytoremediation using duckweed," in Eutrophication: Causes, Consequences and Control, pp. 341-354, Springer, Dordrecht, Netherlands, 2011.

[13] L. L. Rusoff, E. W. Blakeney Jr., and D. D. Culley Jr., "Duckweeds (Lemnaceae family): a potential source of protein and amino acids," Journal of Agricultural and Food Chemistry, vol. 28, no. 4, pp. 848-850, 1980.

[14] E. Yılmaz, İ. Akyurt, and G. Günal, "Use of duckweed, Lemna minor, as a protein feedstuff in practical diets for common carp, Cyprinus carpio, fry," Turkish Journal of Fisheries and Aquatic Sciences, vol. 4, no. 2, pp. 105-109, 2004.

[15] F. Tezcan, S. Uzasci, G. Uyar, N. Öztekin, and F. B. Erim, "Determination of amino acids in pomegranate juices and fingerprint for adulteration with apple juices," Food Chemistry, vol. 141, no. 2, pp. 1187-1191, 2013.

[16] G. V. V. Liyanaarachchi, K. R. R. Mahanama, H. Somasiri, and P. A. N. Punyasiri, "Validation of a reversed-phase highperformance liquid chromatographic method for the determination of free amino acids in rice using l-theanine as the internal standard," Food Chemistry, vol. 240, pp. 196-203, 2018.

[17] Y. Q. Jing, B. L. Zhang, X. X. Yuan et al., "Determination of free amino acids in burley tobacco by high performance liquid chromatography," Saudi Journal of Biological Sciences, vol. 23, no. 1, pp. S64-S68, 2016.

[18] J. A. Hogenboom, P. D'Incecco, F. Fuselli, and L. Pellegrino, "Ion-exchange chromatographic method for the determination of the free amino acid composition of cheese and other dairy products: an inter-laboratory validation study," Food Analytical Methods, vol. 10, no. 9, pp. 3137-3148, 2017.

[19] Y. C. Zhu, Y. H. Luo, P. P. Wang et al., "Simultaneous determination of free amino acids in $\mathrm{Pu}$-erh tea and their changes during fermentation," Food Chemistry, vol. 194, pp. 643-649, 2016.

[20] Z. L. Dai, Z. L. Wu, S. C. Jia, and G. Y. Wu, "Analysis of amino acid composition in proteins of animal tissues and foods as precolumn o-phthaldialdehyde derivatives by HPLC with fluorescence detection," Journal of Chromatography B, vol. 964, pp. 116-127, 2014.

[21] T. Luo, J. Ke, Y. F. Xie, and Y. M. Dong, "Determination of underivatized amino acids to evaluate quality of beer by capillary electrophoresis with online sweeping technique," Journal of Food and Drug Analysis, vol. 25, no. 4, pp. 789-797, 2017.

[22] X. Y. Lai, J. A. Kline, and M. Wang, "Development, validation, and comparison of four methods to simultaneously quantify l-arginine, citrulline, and ornithine in human plasma using hydrophilic interaction liquid chromatography and electrospray tandem mass spectrometry," Journal of Chromatography B, vol. 1005, pp. 47-55, 2015.

[23] H. C. M. T. Prinsen, B. G. M. Schiebergen-Bronkhorst, M. W. Roeleveld et al., "Rapid quantification of underivatized amino acids in plasma by hydrophilic interaction liquid chromatography (HILIC) coupled with tandem mass-spectrometry," Journal of Inherited Metabolic Disease, vol. 39, no. 5, pp. 651-660, 2016.

[24] K. Inoue, Y. Miyazaki, K. Unno et al., "Stable isotope dilution HILIC-MS/MS method for accurate quantification of glutamic acid, glutamine, pyroglutamic acid, GABA and theanine in mouse brain tissues," Biomedical Chromatography, vol. 30, no. 1, pp. 55-61, 2016.

[25] T. Nemkov, A. D'Alessandro, and K. C. Hansen, "Threeminute method for amino acid analysis by UHPLC and high-resolution quadrupole orbitrap mass spectrometry," Amino Acids, vol. 47, no. 11, pp. 2345-2357, 2015.

[26] N. Borisjuk, P. Chu, R. Gutierrez et al., "Assessment, validation and deployment strategy of a two-barcode protocol for facile genotyping of duckweed species," Plant Biology, vol. 17, no. 1, pp. 42-49, 2015.

[27] Y. L. Xu, S. Ma, M. Huang et al., "Species distribution, genetic diversity and barcoding in the duckweed family (Lemnaceae)," Hydrobiologia, vol. 741, no. 1, pp. 75-87, 2015.

[28] H. L. Xue, Y. Xiao, Y. L. Jin et al., "Genetic diversity and geographic differentiation analysis of duckweed using intersimple sequence repeat markers," Molecular Biology Reports, vol. 39, no. 1, pp. 547-554, 2012.

[29] I. Abdel-Qader, S. Pashaie-Rad, O. Abudayyeh, and S. Yehia, "PCA-based algorithm for unsupervised bridge crack detection," Advances in Engineering Software, vol. 37, no. 12, pp. 771-778, 2006.

[30] W. Gao, H. Yang, L. W. Qi et al., "Unbiased metabolite profiling by liquid chromatography-quadrupole time-of-flight mass spectrometry and multivariate data analysis for herbal authentication: classification of seven Lonicera species flower buds," Journal of Chromatography A, vol. 1245, pp. 109-116, 2012.

[31] B. Worley, S. Halouska, and R. Powers, "Utilities for quantifying separation in PCA/PLS-DA scores plots," Analytical Biochemistry, vol. 433, no. 2, pp. 102-104, 2013.

[32] J. Boccard and D. N. Rutledge, "A consensus orthogonal partial least squares discriminant analysis (OPLS-DA) strategy for multiblock Omics data fusion," Analytica Chimica Acta, vol. 769, pp. 30-39, 2013. 


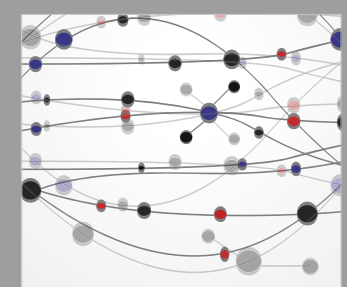

The Scientific World Journal
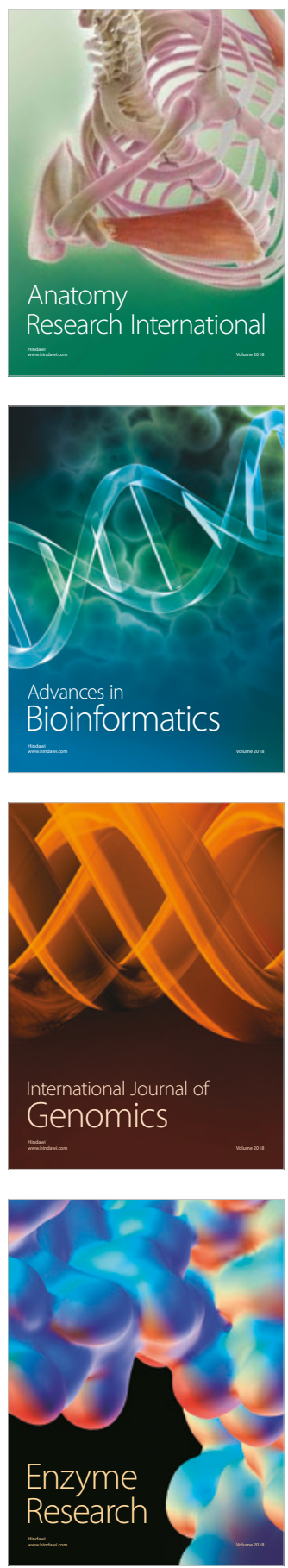
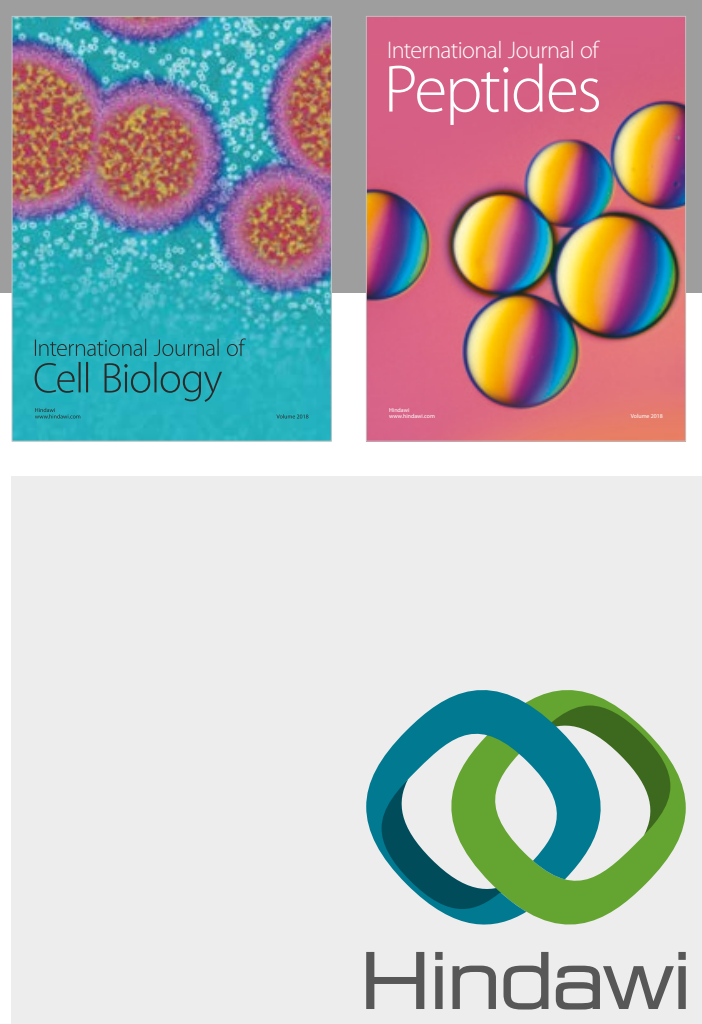

Submit your manuscripts at

www.hindawi.com
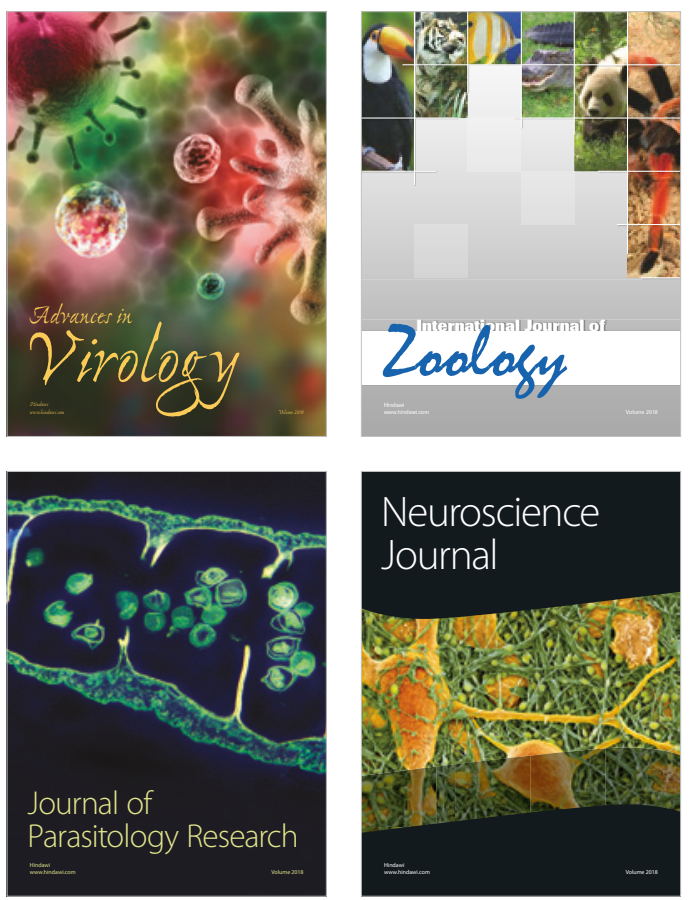
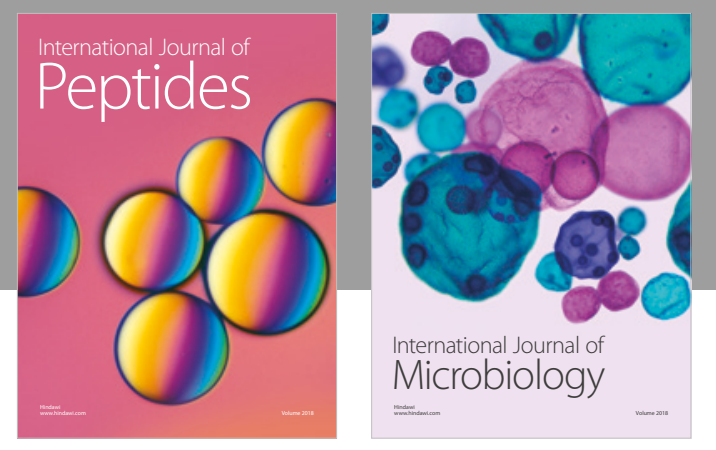

nternational Journal of Microbiology
Journal of
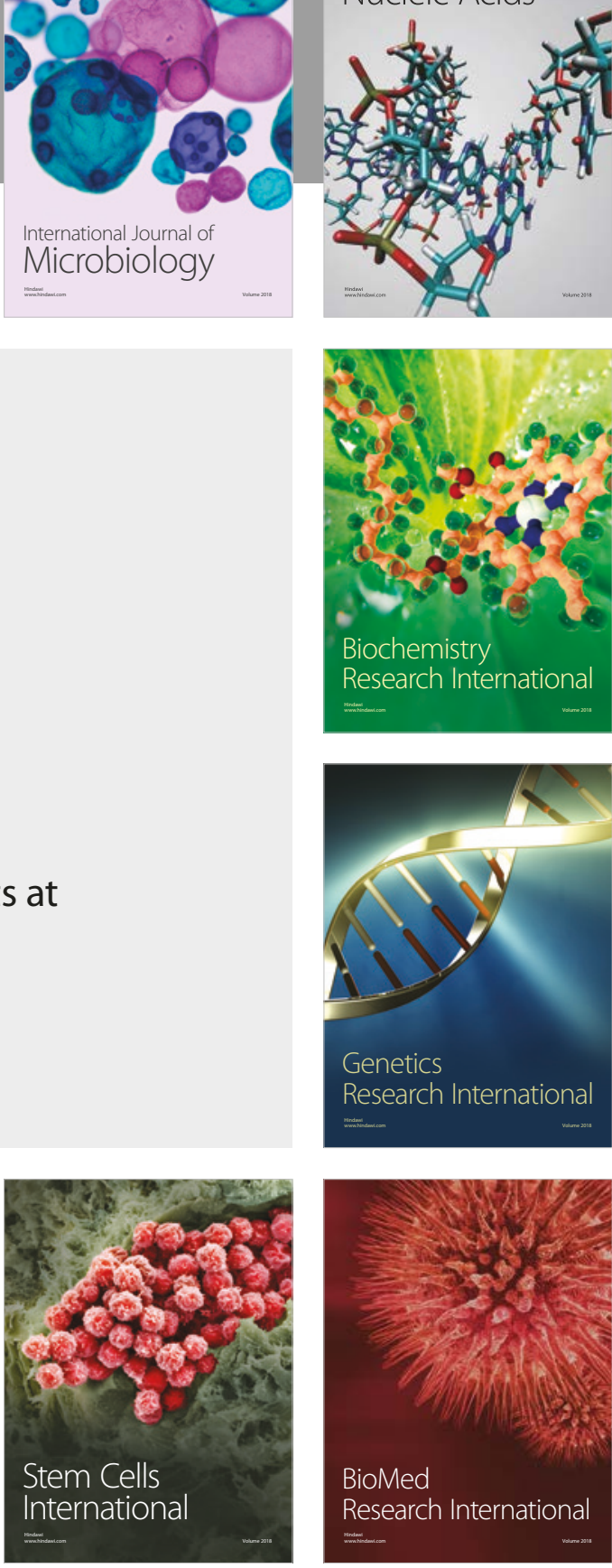
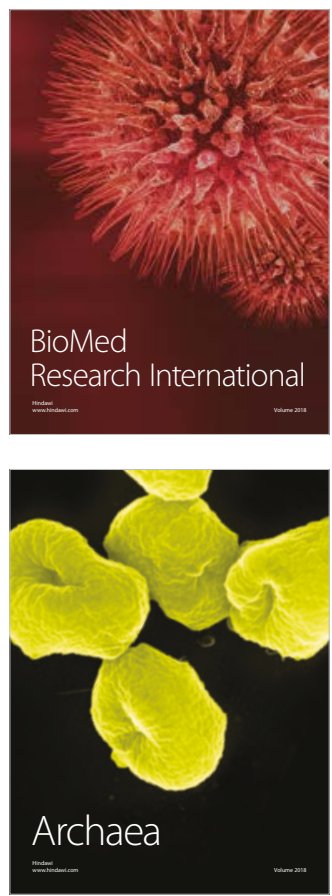